\title{
Interaction of $A D I P O Q$ Genetic Polymorphism With Blood Pressure and Plasma Cholesterol Level on the Risk of Coronary Artery Disease
}

\author{
Yi-Cheng Chang, MD \\ Fu-Tien Chiang, MD, PhD**; Juey-Jen Hwang, MD, PhD**; \\ Wen-Pin Lien, $\mathrm{MD}^{* *}$; Lee-Ming Chuang, MD, PhD**,†
}

\begin{abstract}
Background: The protective effect of $+45 T>G$ polymorphism in the adiponectin gene $(A D I P O Q)$ on coronary artery disease $(\mathrm{CAD})$ has been demonstrated in European populations, so this study investigated the effect of $+45 T>G$ polymorphism on the risk of CAD and its interactions with other metabolic risk factors in a Chinese population.

Methods and Results: The $+45 T>G$ polymorphism (rs2241766) of $A D I P O Q$ was genotyped in 600 patients with angiographically diagnosed CAD and in 718 controls. The $\mathrm{G}$ allele at the $+45 T>G$ polymorphism was associated with a lower risk of CAD (odds ratio (OR), 0.76; 95\% confidence interval (CI), 0.64-0.89; $\mathrm{P}=0.001$ ). The protective effect of the $\mathrm{G}$ allele at $+45 T>G$ polymorphism was magnified at blood pressure $<140 / 90 \mathrm{mmHg}$ $(\mathrm{OR}, 0.65 ; 95 \% \mathrm{CI}, 0.51-0.82 ; \mathrm{P}=0.0004)$, but disappeared at blood pressure $\geq 140 / 90 \mathrm{mmHg}(\mathrm{OR}, 0.98 ; 95 \% \mathrm{CI}$, $0.76-1.28 ; \mathrm{P}=0.93)$, indicating an interaction between $+45 T>G$ polymorphism and blood pressure on CAD risk ( $\mathrm{P}=0.02$ for interaction). A similar interaction was also observed between plasma cholesterol level and the $+45 T>G$ polymorphism.
\end{abstract}

Conclusions: An association of $A D I P O Q$ genetic polymorphism with CAD risk is modified by traditional risk factors, such as blood pressure and plasma cholesterol level. (Circ J 2009; 73: 1934-1938)

Key Words: $A D I P O Q$; Blood pressure; Chinese; Cholesterol; Coronary artery disease; Interaction; Single nucleotide polymorphism

A diponectin, an adipocyte-secreted protein encoded by the $A D I P O Q$ gene (Entrez Gene ID: 9370), exerts insulin-sensitizing and anti-atherogenic effects. ${ }^{1,2}$ A prospective study found that plasma adiponectin concentration is associated with the risk of acute myocardial infarction independent of traditional cardiovascular risk factors. ${ }^{3}$ Cross-sectional studies have also demonstrated a reverse relationship between the total or high-molecular weight form of adiponectin level and risk of coronary artery disease (CAD) or coronary events. ${ }^{4-8}$ Adiponectin inhibits the progression of atherosclerosis in ApoE-deficient mice. ${ }^{9}$ In adiponectin-deficient mice, severe neointimal thickening and proliferation of vascular smooth muscle cells has been observed in mechanically injured arteries while adenovirusmediated supplement of adiponectin attenuated neointimal proliferation..$^{10}$ These findings indicate a protective role of adiponectin in the progression of atherosclerosis.

The adiponectin gene consists of 3 exons and 2 introns spanning a 17-kb region ${ }^{11}$ and has been located on chromosome $3 \mathrm{q} 27$, a genomic region linked with the insulin resistance trait. ${ }^{12}$ Several common genetic variations of the human adiponectin gene have been reported. Among them, a single nucleotide polymorphism (SNP) $+45 T>G$ in exon 2 (rs2241766) of $A D I P O Q$ has been extensively studied. ${ }^{13,14}$ The $\mathrm{G}$ allele at the $+45 T>G$ polymorphism has been associated with higher serum adiponectin concentrations, ${ }^{15,16}$ higher adiponectin mRNA expression in adipose tissue, ${ }^{17}$ enhanced rosiglitazone reposne on serum adiponectin concentrations, ${ }^{18,19}$ improved insulin sensitivity, ${ }^{20-22}$ and a lower risk of obesity. ${ }^{17}$ Several studies also report a protective effect of the $\mathrm{G}$ allele at the $+45 T>G$ polymorphism on the risk of CAD in European populations. ${ }^{23-25}$ However, no studies have investigated the effect of $+45 T>G$ polymorphism on the risk of CAD in a Chinese population, so we aimed to analyze this, as well as the interaction between various cardiovascular risk factors with $+45 T>G$ polymorphism on CAD risk.

\section{Methods}

\section{Participants}

We recruited 600 participants (478 men, 122 women) with

(Received April 6, 2009; revised manuscript received June 2, 2009; accepted June 4, 2009; released online August 7, 2009)

Department of Internal Medicine, National Taiwan University Hospital Yunlin Branch, Yunlin, *Department of Internal Medicine, Far Eastern Memorial Hospital, **Department of Internal Medicine, National Taiwan University Hospital and Graduate Institute of Clinical Medicine, College of Medicine, National Taiwan University, Taipei, Taiwan

$\dagger \dagger$ The first two authors contributed equally to the work.

Mailing address: Lee-Ming Chuang, MD, PhD, Department of Internal Medicine, National Taiwan University Hospital, No. 7 Chung-Shan South Road, Taipei, Taiwan. E-mail: leeming@ha.mc.ntu.edu.tw

All rights are reserved to the Japanese Circulation Society. For permissions, please e-mail: cj@j-circ.or.jp 
angiographically diagnosed CAD from the National Taiwan University Hospital. The diagnostic criterion for CAD was $>75 \%$ stenosis of at least 1 segment of a major coronary artery found on coronary angiography performed because of clinical angina or abnormal resting ECG, or a documented history of transmural myocardial infarction. We also recruited 718 controls (383 men, 335 women) without a history of atherosclerotic vascular disease from the health check-up service of the hospital (275 participants) and a family cohort of Chinese origin (443 unrelated probands). ${ }^{22}$ The study was approved by the institutional review board and each participant provided written informed consent before enrollment.

\section{Demographic and Biochemical Measurements}

We measured the body weight and height of participants while they wore light clothing and had bare feet. Blood pressure (BP) was measured using a mercury sphygmomanometer on 3 separate intervals. Blood was taken in the fasting state for measurements of plasma glucose, total cholesterol and triglyceride levels using an autoanalyzer (Hitachi 7250 Special, Tokyo, Japan).

\section{DNA Extraction and Genotyping of $+45 T>G$ \\ Polymorphism of $A D I P O Q$}

Genomic DNA was prepared from frozen whole blood using a Puregene kit (Promega, Madison, NY, USA). The $+45 T>G$ polymorphism of $A D I P O Q$ was genotyped using the polymerase chain reaction-restriction fragmented length polymorphism method as described previously. ${ }^{17,22}$

\section{Statistical Analysis}

All data are expressed as mean \pm standard deviation. Differences in continuous parameters, such as age, between the 2 groups were analyzed using Student's t-test. The allelic and genotypic association with CAD and OR estimation was analyzed using the chi-squared test with the TT genotype as the reference genotype. Univariate or multivariate logistic regression was used to estimate the unadjusted and adjusted association for other known CAD risk factors, including age, sex, body mass index (BMI), total cholesterol, triglyceride, $\mathrm{BP}$, fasting plasma glucose, and current smoking. A P value $<0.05$ was considered statistically significant.

\section{Results}

\section{Clinical Characteristics of Study Participants}

The clinical characteristics of the study participants are shown in Table 1. Participants with CAD were older and had higher BP, plasma total cholesterol, triglyceride, and fasting glucose levels than the controls. There were also
Table 1. Clinical Characteristics of the Study Participants According to CAD

\begin{tabular}{lccc}
\hline & $\begin{array}{c}\text { Control } \\
(\mathrm{n}=718)\end{array}$ & $\begin{array}{c}\text { CAD cases } \\
(\mathrm{n}=600)\end{array}$ & P value \\
\hline Male $(\mathrm{n})$ & $53.4 \%(383)$ & $78.3 \%(470)$ & $<0.0001$ \\
Age $($ years $)$ & $51.10 \pm 10.38$ & $63.77 \pm 12.10$ & $<0.0001$ \\
Body mass index $\left(\mathrm{kg} / \mathrm{m}^{2}\right)$ & $25.00 \pm 3.37$ & $24.96 \pm 3.41$ & 0.52 \\
Systolic BP $(\mathrm{mmHg})$ & $132.3 \pm 21.7$ & $139.7 \pm 19.71$ & $<0.0001$ \\
Diastolic BP $(\mathrm{mmHg})$ & $79.6 \pm 12.1$ & $82.38 \pm 11.21$ & 0.003 \\
Total cholesterol $(\mathrm{mg} / \mathrm{dl})$ & $192.7 \pm 39.2$ & $205.5 \pm 46.89$ & $<0.001$ \\
Triglyceride $(\mathrm{mg} / \mathrm{dl})$ & $133.9 \pm 88.6$ & $175.4 \pm 110.5$ & $<0.001$ \\
Fasting glucose $(\mathrm{mg} / \mathrm{dl})$ & $92.6 \pm 15.1$ & $119.5 \pm 46.57$ & $<0.0001$ \\
Smoking $(\mathrm{n})$ & $23.8 \%(99)$ & $52.9 \%(317)$ & $<0.0001$ \\
\hline
\end{tabular}

$\mathrm{CAD}$, coronary artery disease; $\mathrm{BP}$, blood pressure.

more men and current smokers among the CAD cases.

\section{Association of $+45 T>G$ Polymorphism of $A D I P O Q$ With CAD and Other CAD Risk Factors}

The genotype distribution of $+45 T>G$ polymorphism was within the Hardy-Weinberg equilibrium in both CAD cases and controls. The $\mathrm{G}$ allele at the $+45 T>G$ polymorphism was associated with a lower risk of CAD (odds ratio (OR), 0.76 ; 95\% confidence interval (CI), 0.64-0.89; $\mathrm{P}=0.001$; Table 2). The OR was 0.78 (95\%CI, 0.61-0.98; $\mathrm{P}=0.03$ ) for the GT genotype and 0.57 (95\%CI, 0.37-0.86; $\mathrm{P}=0.005$ ) for the GG genotype (Table 2). The genetic model was best fit with an additive model. The $\mathrm{G}$ allele was associated with a trend of lower systolic BP ( $\mathrm{P}=0.07)$, but was not associated with other metabolic phenotypes, including diastolic BP $(\mathrm{P}=0.22)$, BMI $(\mathrm{P}=0.90)$, fasting plasma glucose $(\mathrm{P}=$ $0.19)$, triglyceride $(\mathrm{P}=0.78)$, or total cholesterol $(\mathrm{P}=0.37)$ level in the control group. The association of the $\mathrm{G}$ allele with CAD was attenuated, but still significant, after adjustment for known CAD risk factors (adjusted OR, 0.75; 95\%CI, 0.57-0.98; P=0.03; Table 3).

\section{Interactions of $+45 T>G$ Polymorphism With Other CAD Risk Factors on CAD Risk}

We next examined whether there was any interaction between the $+45 T>G$ polymorphism and traditional risk factors on the risk of CAD. An interaction between $+45 T>G$ polymorphism and BP was noted. The $\mathrm{G}$ allele was associated with a significantly lower risk of $\mathrm{CAD}$ in participants with $\mathrm{BP}<140 / 90 \mathrm{mmHg}(\mathrm{OR}, 0.65$; 95\% CI, 0.51-0.82; $\mathrm{P}=0.0004)$, but the protective effect disappeared in participants with $\mathrm{BP} \geq 140 / 90 \mathrm{mmHg}$ (OR, 0.98; 95\%CI, 0.761.28; $\mathrm{P}=0.93$ ), indicating an interaction between $\mathrm{BP}$ and $+45 T>G$ polymorphism on $\mathrm{CAD}$ risk $(\mathrm{P}=0.02$ for interaction) (Figure B).

A similar interaction was also found between plasma

Table 2. Genotypic and Allelic Associations of $A D I P O Q+45 T>G$ Polymorphism With CAD

\begin{tabular}{lrccl}
\hline & Controls, $\mathrm{n}(\%)$ & CAD cases, $\mathrm{n}(\%)$ & OR (95\%CI) & P value \\
\hline Genotype & & & & \\
TT & $309(44.98)$ & $316(52.67)$ & & \\
TG & $299(43.52)$ & $238(39.67)$ & $0.78(0.61-0.98)$ & 0.03 \\
GG & $79(11.50)$ & $46(6.67)$ & $0.57(0.37-0.86)$ & 0.005 \\
Allele & $917(66.73)$ & $870(0.725)$ & & \\
T & $457(33.27)$ & $330(0.275)$ & $0.76(0.64-0.89)$ & 0.001 \\
G & &
\end{tabular}

OR, odds ratio; $\mathrm{CI}$, confidence interval. Other abbreviation see in Table 1. 
Table 3. Adjusted and Unadjusted ORs for Risk Factors of CAD

\begin{tabular}{lcccccc}
\hline \multirow{2}{*}{ Variables } & \multicolumn{2}{c}{ Unadjusted } & & \multicolumn{2}{c}{ Adjusted } \\
\cline { 2 - 3 } \cline { 5 - 6 } & OR $(95 \% \mathrm{CI})$ & $\mathrm{P}$ value & & $\mathrm{R}(95 \% \mathrm{CI})$ & $\mathrm{P}$ value \\
\hline +45T $>G$ polymorphism (each additional G alelle) & $0.76(0.64-0.89)$ & 0.001 & & $0.75(0.57-0.98)$ & 0.03 \\
Male sex & $3.45(2.69-4.41)$ & $<0.0001$ & & $2.49(1.61-3.87)$ & $<0.0001$ \\
Age (per decade) & $2.56(2.27-2.87)$ & $<0.0001$ & & $3.39(2.78-4.13)$ & $<0.0001$ \\
Body mass index (per SD increase) & $0.96(0.87-1.07)$ & 0.52 & & $0.83(0.70-0.99)$ & 0.04 \\
Systolic BP (per SD increase) & $1.33(1.19-1.49)$ & $<0.0001$ & & $0.92(0.71-1.18)$ & 0.49 \\
Diastolic BP (per SD increase) & $1.18(1.06-1.32)$ & 0.003 & & $1.33(1.04-1.72)$ & 0.04 \\
Total cholesterol (per SD increase) & $1.37(1.21-1.55)$ & $<0.0001$ & & $1.38(1.12-1.68)$ & 0.002 \\
Triglyceride (per SD increase) & $1.59(1.39-1.82)$ & $<0.0001$ & & $1.33(1.08-1.65)$ & 0.007 \\
Fasting glucose (per SD increase) & $5.46(4.09-7.30)$ & $<0.0001$ & & $4.11(2.85-5.91)$ & $<0.0001$ \\
Current smoking & $5.90(4.51-7.72)$ & $<0.0001$ & & $5.08(3.34-7.73)$ & $<0.0001$ \\
\hline
\end{tabular}

SD, standard deviation. Other abbreviations see in Table 1.

A

$S B P / D B P \geq 140 / 90 \mathrm{mmHg}$

$+45 T>G$ genotype

$T / T$

T/G

G/G

Coronary artery

disease No. (\%)

Control Case

119(51.3) 173(52.7)

$94(40.5) \quad 125(38.1)$

19(8.2) 30(9.1)

SBP/ DBP $<140 / 90 \mathrm{mmHg}$

$T / T$

T/G

190(41.7)

$43(52.6)$

G/G

205(45.1)

$113(41.5)$

60(13.2)

16(5.9)

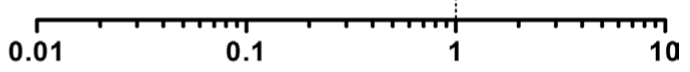

Per-G allele Odds Ratio $(95 \% \mathrm{Cl})$

B

\begin{tabular}{ccc} 
Total cholesterol $\geq 200 \mathrm{mg} / \mathrm{dI}$ & \multicolumn{2}{c}{$\begin{array}{c}\text { Coronary artery } \\
\text { disease No. (\%) }\end{array}$} \\
$+45 T>$ G genotype & Control & Case \\
T/T & $121(46.6)$ & $143(52.5)$ \\
T/G & $112(43.1)$ & $101(37.1)$ \\
G/G & $27(10.4)$ & $28(10.3)$
\end{tabular}

Total cholesterol $<200 \mathbf{~ m g} / \mathrm{dl}$

$T / T$

187(44.0)

186(43.7)

138(52.7)

T/G

52(12.2)

114(41.8)

12(5.5)

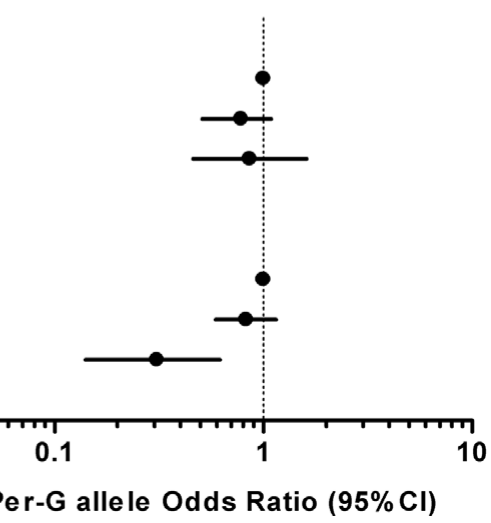

Figure. Interaction between $A D I P O Q+45 T>G$ polymorphism with (A) blood pressure and (B) plasma total cholesterol level on the odds ratio of coronary artery disease. SBP, systolic blood pressure; DBP, diastolic blood pressure; CI, confidence interval.

total cholesterol level and $+45 T>G$ polymorphism. The protective effect of the $\mathrm{G}$ allele was magnified in participants with a plasma total cholesterol level $<200 \mathrm{mg} / \mathrm{dl}$ (OR, 0.68; 95\% CI, 0.53-0.87; $\mathrm{P}=0.001$ ), but disappeared when the total cholesterol level was $\geq 200 \mathrm{mg} / \mathrm{dl}$ (OR, 0.87 ; $95 \% \mathrm{CI}, 0.68-1.13 ; \mathrm{P}=0.29)$, indicating a interaction between $A D I P O Q$ polymrophism and the plasma total cholesterol level on CAD risk ( $\mathrm{P}=0.03$ for interaction) (Figure $\mathbf{A})$. It is of note that the correlation between plasma cholesterol level and mean BP was weak in the present study (correlation coefficient, 0.06). There was no significant interaction between the $+45 T>G$ polymorphism and other CAD risk factors (data not shown). 


\section{Discussion}

The present study showed that $A D I P O Q+45 T>G$ polymorphism is significantly associated with $\mathrm{CAD}$, independent of known CAD risk factors, in the Chinese population of Taiwan. Furthermore, the protective effect of the $\mathrm{G}$ allele at $+45 T>G$ polymorphism is modified by BP and plasma cholesterol level, which indicates that there are interactions between genetic factors and traditional risk factors.

Consistent with our findings, the $\mathrm{G}$ allele of the $+45 T>G$ polymorphism has been associated with lower risk of CAD in European ${ }^{23}$ and US populations. ${ }^{24}$ The protective effect of the $\mathrm{G}$ allele was also found in type 2 diabetic patients. ${ }^{25}$ However, other studies have reported contradictory results in the general population or in type 2 diabetic patients. ${ }^{26-32}$ The discrepancy might be explained by differences in disease definition and ethnic background. However, given the strong influence of BP and plasma cholesterol level on the genetic effect of the $\mathrm{G}$ allele, it is also possible that the prevalence of hypercholesterolemia, hypertension and therapeutic intensity differed in the other studies and interfered with the observed associations. A larger study taking into account the modulating effects of metabolic factors is needed to clarify the association.

The mechanism of how the $+45 T>G$ polymorphism of $A D I P O Q$ relates to $C A D$ risk remains to be determined. The $\mathrm{G}$ allele at the $+45 T>G$ polymorphism has been associated with improved insulin sensitivity and a lower risk of obesity, which may in turn reduce CAD risk. ${ }^{17,20-22}$ However, the $G$ allele was not significantly associated with BMI or other insulin resistance-related metabolic traits in the control group of the present study. The lack of association may be a result of the homogeneity and limited size of the control group. However, the protective effect of $\mathrm{G}$ allele on CAD risk remained significant by adjustment of other metabolic risk factors, indicating an independent effect of $A D I P O Q$ genetic polymorphism on CAD risk.

In support of the findings, adiponectin has been shown to exert direct anti-atherosclerotic effects through mechanisms independent of a systemic insulin-sensitizing effect. Adiponectin suppresses monocyte adhesion to endothelial cells, 33 lipid accumulation in macrophages, foam cell formation, ${ }^{34}$ and proliferation and migration of smooth muscle cells. ${ }^{10,35}$ It also modulates the function of endothelial progenitor cells and endothelial cells. ${ }^{36,37}$ The overlapping of cellular pathways by which adiponectin, cholesterol, and BP modulate atherosclerosis also provides a molecular basis for the observed interaction. Recently, a similar interaction has been observed between the 9p21 locus and poor glycemic control on the risk of CAD. ${ }^{38}$ These findings demonstrate the complex interactions between genetic factors and traditional CAD risk factors in the development of atherosclerosis.

The $+45 T>G$ polymorphism of the human adiponectin gene is a synonymous mutation (GGT $\rightarrow$ GGG, Gly $\rightarrow$ Gly) and the way in which this synonymous mutation influences metabolic phenotypes remains to be elucidated. We previously demonstrated that relative adiponectin mRNA levels were higher in in the adipose tissue of carriers with the $G$ allele. ${ }^{17}$ The $\mathrm{G}$ allele was also associated with significantly higher circulating adiponectin levels. ${ }^{15,16}$ These findings provide a biological basis for the protective effect of this silent polymorphism. The $+45 T>G$ polymorphism is located in a linkage disequilibrium (LD) block spanning from the intron 1 to exon 3 of the adiponectin gene. ${ }^{11,39}$ It is also possible that other genetic variants in the LD with the $+45 T>G$ polymorphism are causal variants for the association.

\section{Study Limitations}

First, the analyses of interactions between $+45 T>G$ genotype and BP or plasma cholesterol level were based on post hoc analyses, raising the concern of false-positive results. Second, the plasma adiponectin concentration was not measured and thus the pathophysiologic mechanism underlying the association could not be further dissected. Third, the controls were selected based on the absence of their past CAD history. Therefore, a small proportion of individuals in the control group might have had subclinical atherosclerosis. The control participants were also significantly younger and there were more women than among the CAD participants. However, such misclassification or mismatch, if present, would have biased the results towards the null hypothesis and the significance level would be underestimated. Furthermore, the association of the $+45 T>G$ polymorphism with CAD has been further adjusted for age, gender, and other metabolic factors. Fourth, only 1 SNP was genotyped in this study. A more comprehensive coverage of SNPs in $A D I P O Q$ would provide more information regarding the role of $A D I P O Q$ genetic polymorphism in CAD risk. Finally, drug information was missing for some participants, so interference by drug therapy could not be analyzed or excluded. However, as most CAD patients receive anti-hypertensive or lipid-lowering therapy, the present study is actually more applicable to common daily practice.

In conclusion, the present study demonstrates that the $+45 T>G$ polymorphism of $A D I P O Q$ is associated with $\mathrm{CAD}$, independent of other known risk factors. The association is strongly modified by BP and plasma cholesterol level. The findings highlight the importance of gene-environment interaction in the development of complex disorders.

\section{Acknowledgments}

We thank all the participants in this study. We also thank Ms SS Kuo and Ms KC Lee for their technical support.

This work was supported in part by grants from the National Science Council of the R.O.C. (NSC 92-3112-B-002-015; NSC 93-2752-B-002009-PAE)

\section{References}

1. Matsuzawa Y. Adiponectin: Identification, physiology and clinical relevance in metabolic and vascular disease. Atheroscler Suppl 2005; 6: $7-14$.

2. Shibata R, Ouchi N, Murohara T. Adiponectin and cardiovascular disease. Circ J 2009; 73: 608-614.

3. Pischon T, Girman CJ, Hotamisligil GS, Rifai N, Hu FB, Rimm EB. Plasma adiponectin levels and risk of myocardial infarction in men. JAMA 2004; 291: 1730-1737.

4. Kumada M, Kihara S, Sumitsuji S, Kawamoto T, Matsumoto S, Ouchi N, et al. Coronary artery disease: Association of hypoadiponectinemia with coronary artery disease in men. Arterioscler Thromb Vasc Biol 2003; 23: 85-89.

5. Kojima S, Funahashi T, Sakamoto T, Miyamoto S, Soejima H, Hokamaki J, et al. The variation of plasma concentration of a novel, adipocyte derived protein, adiponectin, in patients with acute myocardial infarction. Heart 2003; 89: 667.

6. Dzielinska Z, Januszewicz A, Wiecek A, Demkow M, MakowieckaCiesla M, Prejbisz A, et al. Decreased plasma concentration of a novel anti-inflammatory protein--adiponectin--in hypertensive men with coronary artery disease. Thromb Res 2003; 110: 365-369.

7. Komura N, Kihara S, Sonoda M, Kumada M, Fujita K, Hiuge A, et al. Clinical significance of high-molecular weight form of adiponectin in 
male patients with coronary artery disease. Circ J 2008; 72: 23-28.

8. Shioji K, Moriwaki S, Takeuchi Y, Uegaito T, Mutsuo S, Matsuda M Relationship of serum adiponectin level to adverse cardiovascular events in patients undergoing percutaneous coronary intervention. Circ J 2007; 71: 675-680.

9. Yamauchi T, Kamon J, Waki H, Imai Y, Shimozawa N, Hioki K, et al. Globular adiponectin protected ob/ob mice from diabetes and ApoEdeficient mice from atherosclerosis. J Biol Chem 2003; 278: 2461 2468.

10. Matsuda M, Shimomura I, Sata M, Arita Y, Nishida M, Maeda N, et al. Role of adiponectin in preventing vascular stenosis: The missing link of adipo-vascular axis. J Biol Chem 2002; 277: 37487-37491.

11. Takahashi M, Arita Y, Yamagata K, Matsukawa Y, Okutomi K, Horie M, et al. Genomic structure and mutations in adipose-specific gene, adiponectin. Int J Obes Relat Metab Disord 2000; 24: 861 868.

12. Kissebah AH, Sonnenberg GE, Myklebust J, Goldstein M, Broman $\mathrm{K}$, James RG, et al. Quantitative trait loci on chromosomes 3 and 17 influence phenotypes of the metabolic syndrome. Proc Nat Acad Sci USA 2000; 97: 14478-14483.

13. Menzaghi C, Trischitta V, Doria A. Genetic influences of adiponectin on insulin resistance, type 2 diabetes, and cardiovascular disease. Diabetes 2007; 56: $1198-1209$.

14. Yang WS, Chuang LM. Human genetics of adiponectin in the metabolic syndrome. J Mol Med 2006; 84: 112-121.

15. Mackevics V, Heid IM, Wagner SA, Cip P, Doppelmayr H, Lejnieks $\mathrm{A}$, et al. The adiponectin gene is associated with adiponectin levels but not with characteristics of the insulin resistance syndrome in healthy Caucasians. Eur J Hum Genet 2006; 14: 349-356.

16. Berthier MT, Houde A, Cote M, Paradis AM, Mauriege P, Bergeron J, et al. Impact of adiponectin gene polymorphisms on plasma lipoprotein and adiponectin concentrations of viscerally obese men. J Lipid Res 2005; 46: 237-244.

17. Yang WS, Tsou PL, Lee WJ, Tseng DL, Chen CL, Peng CC, et al. Allele-specific differential expression of a common adiponectin gene polymorphism related to obesity. J Mol Med 2003; 81: 428-434.

18. Sun H, Gong ZC, Yin JY, Liu HL, Liu YZ, Guo ZW, et al. The association of adiponectin allele $45 \mathrm{~T} / \mathrm{G}$ and $-11377 \mathrm{C} / \mathrm{G}$ polymorphisms with Type 2 diabetes and rosiglitazone response in Chinese patients. Br J Clin Pharmacol 2008; 65: 917-926.

19. Zhang H, Jia WP, Hu C, Zhang R, Wang CR, Bao YQ, et al. The effect of single nucleotide polymorphism SNP +45 of the adiponectin gene on the rosiglitazone maleate response in patients with type 2 diabetes. Zhonghua Yi Xue Za Zhi 2007; 87: 2390-2393.

20. Menzaghi C, Ercolino T, Di Paola R, Berg AH, Warram JH, Scherer $\mathrm{PE}$, et al. A haplotype at the adiponectin locus is associated with obesity and other features of the insulin resistance syndrome. Diabetes 2002; 51: 2306-2312.

21. Ruchat SM, Loos RJ, Rankinen T, Vohl MC, Weisnagel SJ, Despres $\mathrm{JP}$, et al. Associations between glucose tolerance, insulin sensitivity and insulin secretion phenotypes and polymorphisms in adiponectin and adiponectin receptor genes in the Quebec Family Study. Diabet Med 2008; 25: 400-406.

22. Yang WS, Hsiung CA, Ho LT, Chen YT, He CT, Curb JD, et al. Genetic epistasis of adiponectin and PPARgamma2 genotypes in modulation of insulin sensitivity: A family-based association study. Diabetologia 2003; 46: 977-983.

23. Gable DR, Matin J, Whittall R, Cakmak H, Li KW, Cooper J, et al. Common adiponectin gene variants show different effects on risk of cardiovascular disease and type 2 diabetes in European subjects. Ann Hum Genet 2007; 71: 453-466.

24. Pischon T, Pai JK, Manson JE, Hu FB, Rexrode KM, Hunter D, et al.
Single nucleotide polymorphisms at the adiponectin locus and risk of coronary heart disease in men and women. Obesity 2007; 15: 20512060.

25. Qi L, Li T, Rimm E, Zhang C, Rifai N, Hunter D, et al. The +276 polymorphism of the APM1 gene, plasma adiponectin concentration, and cardiovascular risk in diabetic men. Diabetes 2005; 54: 1607 1610.

26. Hegener HH, Lee IM, Cook NR, Ridker PM, Zee RY. Association of adiponectin gene variations with risk of incident myocardial infarction and ischemic stroke: A nested case-control study. Clin Chem 2006; 52: $2021-2027$.

27. Bacci S, Menzaghi C, Ercolino T, Ma X, Rauseo A, Salvemini L, et al. The $+276 \mathrm{G} / \mathrm{T}$ single nucleotide polymorphism of the adiponectin gene is associated with coronary artery disease in type 2 diabetic patients. Diabetes Care 2004; 27: 2015-2020.

28. Jung CH, Rhee EJ, Kim SY, Shin HS, Kim BJ, Sung KC, et al. Associations between two single nucleotide polymorphisms of adiponectin gene and coronary artery diseases. Endocr J 2006; 53: 671-677.

29. Ohashi K, Ouchi N, Kihara S, Funahashi T, Nakamura T, Sumitsuji $\mathrm{S}$, et al. Adiponectin I164T mutation is associated with the metabolic syndrome and coronary artery disease. J Am Coll Cardiol 2004; 43: $1195-1200$.

30. Lacquemant C, Froguel P, Lobbens S, Izzo P, Dina C, Ruiz J. The adiponectin gene $\mathrm{SNP}+45$ is associated with coronary artery disease in Type 2 (non-insulin-dependent) diabetes mellitus. Diabet Med 2004; 21: 776-781.

31. Qi L, Doria A, Manson JE, Meigs JB, Hunter D, Mantzoros CS, et al. Adiponectin genetic variability, plasma adiponectin, and cardiovascular risk in patients with type 2 diabetes. Diabetes 2006; 55: $1512-$ 1516.

32. Filippi E, Sentinelli F, Romeo S, Arca M, Berni A, Tiberti C, et al. The adiponectin gene SNP+276G $>$ T associates with early-onset coronary artery disease and with lower levels of adiponectin in younger coronary artery disease patients (age $\leq 50$ years). J Mol Med 2005; 83: 711-719.

33. Ouchi N, Kihara S, Arita Y, Maeda K, Kuriyama H, Okamoto Y, et al. Novel modulator for endothelial adhesion molecules: Adipocytederived plasma protein adiponectin. Circulation 1999; 100: $2473-$ 2476.

34. Ouchi N, Kihara S, Arita Y, Nishida M, Matsuyama A, Okamoto Y, et al. Adipocyte derived plasma protein, adiponectin, suppresses lipid accumulation and class A scavenger receptor expression in human monocyte-derived macrophages. Circulation 2001; 103: 1057-1063.

35. Arita Y, Kihara S, Ouchi N, Maeda K, Kuriyama H, Okamoto Y, et al. Adipocyte derived plasma adiponectin acts as a platelet derived growth factor-BB-binding protein and regulates growth-induced common post-receptor signal in vascular smooth muscle cell. Circulation 2002; 105: $2893-2898$

36. Matsuo Y, Imanishi T, Kuroi A, Kitabata H, Kubo T, Hayashi Y, et al. Effects of plasma adiponectin levels in the number and function of endothelial progenitor cells in patients with coronary artery disease. Circ J 2007; 9: 1376-1382.

37. Chen H, Montagnani M, Funahashi T, Shimomura I, Quon MJ. Adiponectin stimulates production of nitric oxide in vascular endothelial cells. J Biol Chem 2003; 278: 45021-45026.

38. Doria A, Wojcik J, Xu R, Gervino EV, Hauser TH, Johnstone MT, et al. Interaction between poor glycemic control and 9p21 locus on risk of coronary artery disease in type 2 diabetes. JAMA 2008; 300: $2389-2397$.

39. The International HapMap Consortium: The International HapMap Project. Nature 2003; 426: 789-796. 